\title{
Growth and Physiological Responses of Four Plant Species to Different Sources of Particulate Matter
}

\author{
Kei-Jung Kwon ${ }^{1}$, Uuriintuya Odsuren ${ }^{2}{ }^{\dagger}$, Huong-Thi Bui ${ }^{\dagger}$, Sang-Yong Kim ${ }^{3}$, and Bong-Ju Park ${ }^{4 *}$ \\ ${ }^{1}$ Researcher, Department of Horticultural Science, Chungbuk National University, Cheongju 28864, Korea \\ ${ }^{2}$ Master's student, Major in Horticulture, Graduate School, Chungbuk National University, Cheongju 28864, Korea \\ ${ }^{3}$ Researcher, Division of Plant Resources, Korea National Arboretum, Pocheon 11186, Korea \\ ${ }^{4}$ Professor, Department of Horticultural Science, Chungbuk National University, Cheongju 28864, Korea
}

\section{ABSTRACT}

Background and objective: Particulate matter (PM) has a serious impact on health. Recently, studies are conducted to reduce PM in an environmentally friendly way using plants. This study investigated the physiological responses of plants and their ability to remove PM by continuously spraying different PM sources (loam, fly ash, carbon black) to four native plant species, such as Iris sanguinea, Pteris multifida, Vitis coignetiae, and Viburnum odoratissimum var. awabuki.

Methods: The four plant species were randomly placed in four chambers, and $0.1 \mathrm{~g}$ of different PM was injected into each chamber twice a week. We measured chlorophyll, carotenoid, chlorophyll fluorescence (Fv/Fm), total leaf area, amount of leaf wax, PM10 (sPM10) and PM2.5 (sPM2.5) on the leaf surface, and PM10 (wPM10) and PM2.5 (wPM2.5) on the wax layer. Results: For I. sanguinea and V. coignetiae, the sources of PM did not affect the growth response. P. multifida showed high chlorophyll a, b, total chlorophyll, and carotenoid content in carbon black as well as high Fv/Fm and total leaf area, thereby proving that carbon black helped plant growth. By PM sources, sPM10 showed a significant difference in three plant species, sPM2.5 in two plant species, and WPM10 in one plant species, indicating that sPM10 was most affected by PM sources. Conclusion: Carbon black increased the leaf area by affecting the growth of $P$. multifida. This plant can be effectively used for PM reduction by increasing the adsorption area. I. sanguinea and V. coignetiae can be used as economical landscaping plants since they can grow regardless of PM sources.

Keywords: carbon black, fly ash, landscaping plants, loam, native plants, PM10, PM2.5

\section{Introduction}

Environmental pollution caused by industrialization and urbanization affects human health and has a negative influence on mortality and prevalence rates. In particular, each time the concentration of particulate matter (PM) increases by $10 \mu \mathrm{g} \mathrm{m}^{-3}$, the mortality rates of all illnesses, cardiopulmonary diseases, and lung cancer increase significantly by 4,6 , and $8 \%$ respectively (Ebi and McGregor, 2008; Pope et al., 2002).
To reduce the concentration of air pollutants, the fundamental solution would be to block or eliminate the sources, which is nearly impossible in the modern society. Thus, it is necessary to study methods to reduce the pollutants in an environmentally friendly way.

Atmospheric temperature, relative humidity, and wind velocity have a huge impact on air quality. Plants are also known to affect air quality. Areas without plants have poorer air quality than those with plants, and the quantity of pollutants

\footnotetext{
${ }^{\dagger}$ These authors contributed equally to this work.

This study was carried out with the support of 'R\&D Program for Forest Science Technology (Project No. 201915510-2021-001) provided by Korea Forest Service (Korea Forestry Promotion Institute).

Received: August 26, 2021, Revised: September 24, 2021, Accepted: October 7, 2021

First author: Kei-Jung Kwon, kkj0427@hanmail.net, (1) https://orcid.org/0000-0002-4652-0605

*Corresponding author: Bong-Ju Park, bjpak@chungbuk.ac.kr, (1) https://orcid.org/0000-0001-5511-4812
} 
detected from leaves planted in parks or suburbs is smaller than street trees growing in the city ( $\mathrm{Li}$ et al., 2019; Ottelé et al., 2010). Plants in areas with poor air quality contribute greatly to reducing the quantity of air pollutants, but their survival may also be negatively affected by PM sources. Therefore, many studies are conducted to choose the optimal plant species suitable for sustainable air quality improvement and regional conditions with an excellent air purifying effect. Zhang et al. (2017) studied the relationship between leaf surface characteristics and PM capture capacity of various tree species for a year in Beijing to select the optimal plant species to use in air quality improvement. As a result, the TSP and PM10 capturing capacity of the leaves of Pinus tabuliformis and Pinus bungeana, which are needle-leaved trees, decreased at first but then increased over time, whereas Salix matsudana, Acer truncatum, and Populus tomentosa, which are broad-leaved trees, showed opposite results. Zhang et al. (2020) reported that PM capturing capacity of plants, air pollution tolerance index (APTI), and antioxidant systems can be used as indicators to select suitable plant species in green belt construction. Bui et al. (2021) compared the accumulative amount of PM and APTI with 11 species of woody plants and reported that Pinus strobus showed the highest PM accumulation and APTI, whereas Cercis chinensis showed the lowest.

Urbanization and industrialization are increasing the population staying indoors. Recently, the demand for green buildings is increasing due to the reduction of energy use and greenhouse gas emissions, and the evaluation items of green building certification systems include elements such as indoor pollutants (So and Cho, 2018). Plants serve as dust collector filters for air purification in addition to indoor landscaping, adsorbing and absorbing air pollutants and improving air quality in an environmentally friendly way. Park et al. (2008) conducted an experiment in which they removed formaldehyde using 6 species of ornamental plants and discovered that formaldehyde is removed actively during the day when there is photosynthesis. Moreover, a certain level of concentration that does not damage the plant may also help plant growth. Kim and Yoo (2011) used 3 species of plants such as Deffenbachia, Ficus benjamina, and Chrysalidorcarpus lutescens as well as fine gravel, sand, moss, and Selaginella as the pot covering materials to determine the effect on formaldehyde removal efficiency. As a result, the formaldehyde removal rate was high- est in Deffenbachia regardless of the covering method, and in Selaginella for the covering material. Bang et al. (2013) compared PM10 concentrations in three environments such as the control without plants, indoor green walls, and the 'bio green wall system' with functionality and reported that PM10 concentrations decreased by $62 \%$ and $72 \%$, respectively, in the general green wall and bio green wall system compared to the control without plants.

A study on PM reduction using plants analyzed the quantity and ingredients of PM sources absorbed and adsorbed on plant leaves, which are spontaneously generated yellow dust and pollutants caused by vehicles (Sgrigna, et al., 2020). In indoor or chamber experiments, cigarette smoke, mosquito coils, and test powder are used as PM sources (Jeong et al., 2020; 2021; Kwon and Park, 2017; 2018; Lee et al., 2015; Yoon et al., 2009; Yoon and Kim 2018). PM is comprised of various components such as carbon (carbon black, organic carbon, organism), ion (chlorine, nitric acid, sulfuric acid, ammonium, sodium, etc.), metal (lead, arsenic, cadmium, mercury, etc.), and polycyclic aromatic hydrocarbon, etc. (Dominici et al., 2015). Therefore, this study is conducted to examine the physiological response of plants toward sources of PM (loam, fly ash, carbon black) as well as PM removal capacity of 4 native plant species such as Iris sanguinea, Pteris multifida, Vitis coignetiae, and Viburnum odoratissimum var. awabuki.

\section{Materials and Methods}

\section{Plant materials}

For plant materials, we selected $I$. sanguinea, $P$. multifida, $V$. coignetiaer, and $V$. odoratissimum var. awabuki that were proven to have excellent PM reduction capacity in the studies by Kwon et al. (2020; 2021) (Table 1). Each plants were planted

Table 1. Plants used in the experiment

\begin{tabular}{cccc}
\hline Species & Family & Korean name & Habit \\
\hline Iris sanguinea & Iridaceae & 붓꽃 & Perennial herb \\
Pteris multifida & Pteridaceae & 봉의꼬리 & Evergreen fern \\
itis coignetiae & Vitaceae & 머루 & Deciduous vine \\
$\begin{array}{c}\text { Viburnum } \\
\text { odoratissimum }\end{array}$ & Caprifoliaceae & 아왜나무 & $\begin{array}{c}\text { Evergreen } \\
\text { small tree }\end{array}$ \\
var. awabuki & & & \\
\hline
\end{tabular}


in a plastic pot with a diameter of $15 \mathrm{~cm}$ using horticultural substrate (Wonjo Mix, Nongkyung, Korea) and grew in a greenhouse, and acclimated in a laboratory environment for 2 weeks.

\section{Experiment method and data analysis}

We randomly arranged total 12 pots, 3 pots of each plant, in the acrylic chamber $(800 \times 800 \times 1000 \mathrm{~mm}, \mathrm{~L} \times \mathrm{W} \times \mathrm{H})$ that modeled an indoor space. For photosynthesis of the plants, we installed an LED white light source panel over the acrylic chamber, and the amount of light at the very top of the plants was $75 \mu \mathrm{mol} \mathrm{m} \mathrm{s}^{-2} \mathrm{~s}^{-1}$ PPFD. We installed a fan on the upper part of the light source to reduce the heat from the light source over the chamber and covered the entire chamber with blackout curtains to minimize the effect of light from the outside. The indoor temperature was set at $25^{\circ} \mathrm{C}$ using an air conditioner.

Three PM sources were used: fly ash (JIS Test Powders1 (JIS Z 8901) (Class 10), The Association of Powder Process Industry and Engineering, Japan), loam (JIS Test Powders1 (JIS Z 8901) (Class 11 KANTO (Japanese), The Association of Powder Process Industry and Engineering, Japan), and carbon black (JIS Test Powders1 (JIS Z 8901) (Class 12), The Association of Powder Process Industry and Engineering, Japan). We used the chamber without PM as the control. We put $0.1 \mathrm{~g}$ of PM in the spray container set up at the center of the top part of the chamber, connected the silicone hose to the outside of the chamber, and sprayed it 5 times a minute using an air gun connected to the compressor, after which we concealed it to prevent inflow of outside air. We injected it twice a week for 90 days.

After injecting PM, we measured chlorophyll a (Chl a), chlorophyll b (Chl b), total chlorophyll (Tchl), carotenoid content, and chlorophyll fluorescence (Fv/Fm) 30 days after treatment (DAT), 60 DAT, and 90 DAT. To measure Chl a, Chl b, Tchl, and carotenoid, we froze the leaf samples with liquid nitrogen and crushed them, extracted supernatant using a centrifuge (Cef-6, DAIHAN, Korea) and measured absorbance at the wavelength of $470 \mathrm{~nm}, 646.8 \mathrm{~nm}$, and 663.2 nm using a spectrophotometer (UV-1800, SHIMAZU, Japan). The measured values were calculated using the following Equation (1) according to the method by Lichtenthaler et al. (1987).

$$
\begin{aligned}
\text { Chlorophyll } \mathrm{a}=\left(12.25 \times \mathrm{A}_{663.2}-2.79 \times \mathrm{A}_{646.8}\right) \\
\text { Chlorophyll } \mathrm{b}=\left(21.5 \times \mathrm{A}_{646.8}-5.1 \times \mathrm{A}_{663.2}\right) \\
\begin{aligned}
& \text { Carotinoid }=\left(1000 \times \mathrm{A}_{470}-1.82 \times \mathrm{Chl} \mathrm{a}-85.02 \times\right. \\
&\text { Chl b }) / 198
\end{aligned}
\end{aligned}
$$

Where, $\mathrm{A}_{646.8}$, was absorbance at $646.8 \mathrm{~nm}$ and $\mathrm{A}_{663.2}$, and $\mathrm{A}_{470}$ were absorbance at 663.2 and $470 \mathrm{~nm}$, respectively.

$\mathrm{Fv} / \mathrm{Fm}$ was measured repeatedly 9 times after 30 minutes of dark adaptation using a chlorophyll fluorometer (OS-30P+, Opti-Science, USA). After the experiment, we measured total leaf area, wax content, PM10 (sPM10) and PM2.5 (sPM2.5) on the leaf surface, and PM10 (wPM10) and PM2.5 (wPM2.5) on the wax layer. We measured PM10 and PM2.5 on the leaf surface and wax layer after the experiment using the method by Dzierżanowski et al. (2011). After PM exposure, we collected about $400 \mathrm{~cm}^{2}$ of leaves from each pot and washed them in $250 \mathrm{ml}$ of distilled water, after which we filtered at least $100 \mu \mathrm{m}$ of impurities using a standard screen, then filtered them one by one using 10-100 $\mu \mathrm{m}$ (Whatman No.91) and 2.5-10 $\mu \mathrm{m}$ (Whatman No.42) filter paper. We dried the filter paper in a dryer (HB-502M, Hanbaek Science, Korea) at $80^{\circ} \mathrm{C}$ and measured the weight using a analytical balance (AUW220D, SHIMADZU, Japan). The area of leaves used in the filtering process was measured using a leaf area meter (LI-3100C, LI-CO, USA). We divided the difference in weight before and after drying the filter paper by leaf area and calculated the amount of PM per unit area of each plant as $\mu \mathrm{g} \mathrm{cm}^{-2}$. We measured wax layer PM using the same method as the measurement of surface PM after dissolving the same leaves in chloroform. Wax content was measured by filtering all PM and then using the difference in weight before and after filtration of the remaining solution in the beaker. Leaf area was measured by measuring the area of all leaves overground with a leaf area meter (Li-3000A, LI-COR, USA) after the experiment.

Statistical analysis was conducted using SAS 9.3 (SAS Institute Inc., USA), and Duncan's multiple range test (DMRT) was conducted at a $5 \%$ significance level to determine the difference in means. 


\section{Results and Discussion}

Only $P$. multifida showed a significant difference in Chl a, Chl b, Tchl, and carotenoid content depending on PM sources in 30 DAT, 60 DAT, and 90 DAT, while the other three plants did not show a significant difference (Fig. 1). Even though $I$. sanguinea had sufficient acclimation in the laboratory environment, all of $\mathrm{Chl} \mathrm{a}, \mathrm{Chl} \mathrm{b}$, Tchl, and carotenoid content decreased in 60 DAT and increased in 90 DAT in the control and PM sources treatment during the three-month experiment in the chamber, showing a V-shaped pattern. As a result of cultivating $P$. multifida with different concentrations of arsenic in the soil for phytoremediation, which is a biological treatment technology purifying heavy metal in soil, it was found that growth in 50 and $500 \mathrm{mg} \mathrm{kg}^{-1}$ treatments was similar to the non-treatment regardless of arsenic type; and as arsenic concentrations increased, growth decreased overall compared to non-treatment (Kwon et al., 2015). Chang and Lee (2005) evaluated tolerance to arsenic and reported that growth of $P$. multifida rather increased with low-concentration arsenic compared to non-treatment. In this study, $P$. multifida seems to show good growth conditions with high values of each measurement item in carbon black, whereas there was no difference with the control in fly ash and loam. $V$. coignetiae and $V$. odoratissimum var. awabuki showed a similar pattern of Chl a, Chl b, Tchl, and carotenoid with the control in 30 DAT, 60 DAT, and 90 DAT, showing no significant difference.

Chlorophyll fluorescence reaction shows the effect on environmental stress by nondestructively analyzing the variables detecting quantitative change in photosynthesis photons and the decrease in photosynthesis (Oh et al., 2014). I. sanguinea showed a V-shaped pattern in Fv/Fm over time as did in chlorophyll and carotenoid content regardless of PM sources (Fig. 1), indicating that acclimation takes at least a month. Łukowski et al. (2020) exposed three species of woody plants to PM collected from cement, construction sites, and roads, in which case Fv/Fm was significantly lower than the control. In this study, Fv/Fm of $I$. sanguinea and $V$. coignetiae did not show a significant difference depending on PM sources (Table 2). Fv/Fm of $V$. odoratissimum var. awabuki increased over time in the control, thereby not showing stress, but it decreased over time when carbon black was injected, showing the lowest value at 0.778 in 90 DAT. Therefore, carbon black helped the growth of $V$. odoratissimum var. awabuki up to 30 DAT but inhibited the growth after that. Fv/Fm of $P$. multifida was higher in carbon black and fly ash than the control in 30 DAT, and in carbon black and loam than the control in 60 DAT. There was no significant difference depending on

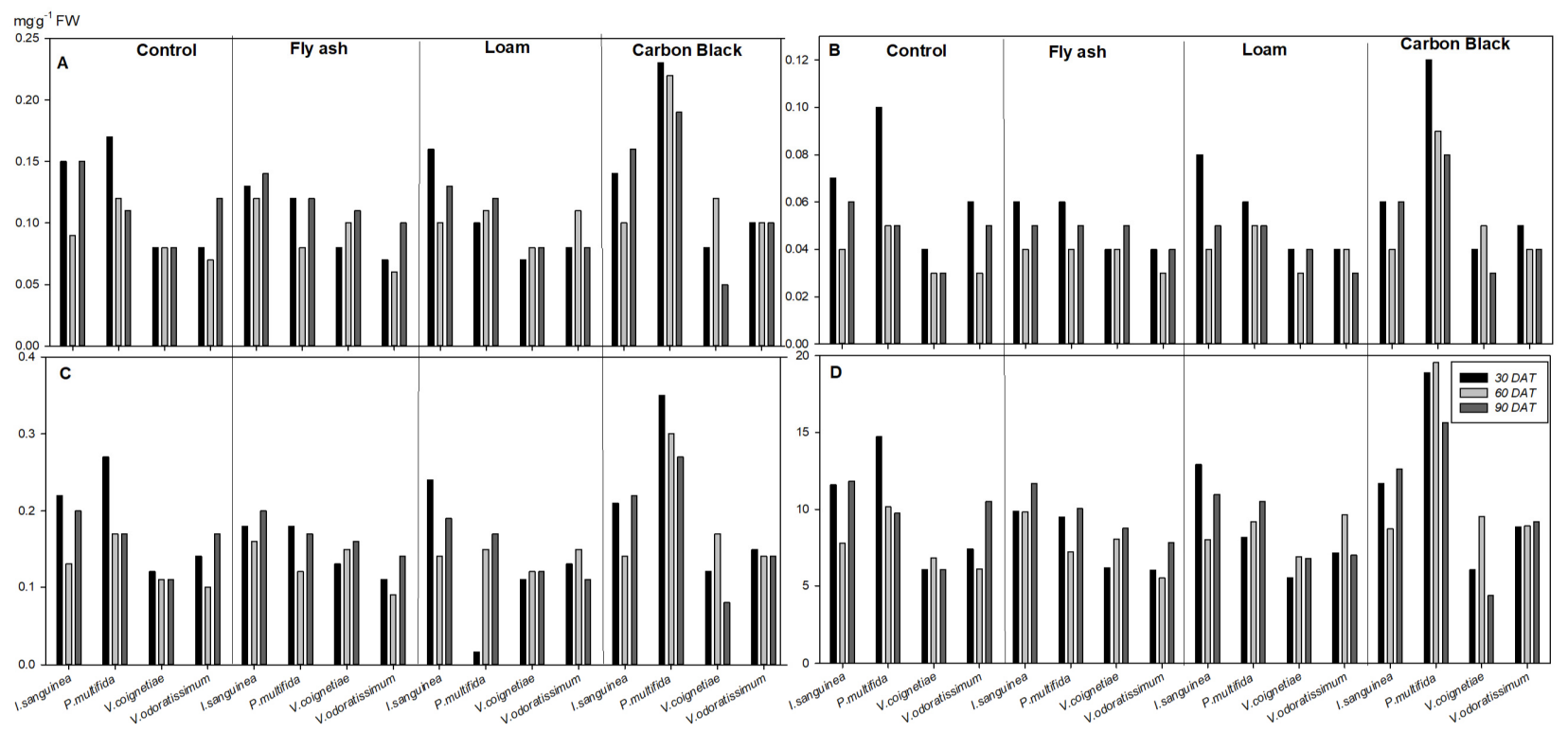

Fig. 1. Comparison of chlorophyll and carotenoid contents according to PM sources. A: Chl a, B: Chl b, C: Tchl, and D: carotenoid. 
PM sources in 90 DAT. This is the same as the result that chlorophyll and carotenoid content of $P$. multifida were highest in 30 DAT in carbon black and decreased over time as shown in Fig. 1.

After the experiment, leaf area did not show a significant difference depending on PM sources in three plant species other than $P$. multifida (Table 3). As a result of continuous exposure to PM sources, $P$. multifida showed 2-3 times wider leaf area in carbon black compared to the control and other PM sources. This may have been affected by high chlorophyll and carotenoid content (Fig. 1) and high Fv/Fm (Table 2). However, P. multifida showed 2/3 survival rate in 90 DAT and carbon black. Growth may have been inhibited by watering the plant with only a certain amount of water despite the rapid increase in leaf area. Park et al. (2008) conducted an experiment on removing formaldehyde from ornamental plants and revealed that a certain level of concentration that does not damage the plant may rather have a positive effect on plant growth. Lukowski et al. (2020) compared shoot length in each PM with the control and discovered that Quercus robur did not show a significant difference by PM sources, whereas Betula pendula and Tilia cordata showed less growth in certain PM sources compared to the control, which indicates that PM sources may promote or inhibit growth, and thus it is necessary to experiment with various PM sources and plants. Wax content of each plant did not show a significant difference by plants and PM sources after the experiment. However, I. sanguinea showed about 2-3 times higher mean in the PM sources than the control,

Table 2. Comparison of chlorophyll fluorescence (Fv/Fm) of each plant according to PM sources

\begin{tabular}{|c|c|c|c|c|c|c|}
\hline DAT & Species & Control & Fly ash & Loam & Carbon black & Significance \\
\hline \multirow{4}{*}{30} & I.sanguinea & $0.784 \pm 0.01 \quad \mathrm{a}^{\mathrm{z}}$ & $0.785 \pm 0.01 \mathrm{a}$ & $0.785 \pm 0.01 \mathrm{a}$ & $0.795 \pm .0 .01 \mathrm{a}$ & ns \\
\hline & P.multifida & $0.790 \pm 0.02 \mathrm{~b}$ & $0.805 \pm 0.01 \mathrm{ab}$ & $0.781 \pm 0.04 \quad b$ & $0.825 \pm 0.01 \mathrm{a}$ & $* *$ \\
\hline & V.coignetiae & $0.777 \pm 0.01 \quad \mathrm{a}$ & $0.778 \pm 0.01 \quad \mathrm{a}$ & $0.770 \pm 0.02 \mathrm{a}$ & $0.786 \pm 0.02 \mathrm{a}$ & ns \\
\hline & V. odoratissimum var. awabuki & $0.778 \pm 0.01 \mathrm{c}$ & $0.797 \pm 0.01 \quad b$ & $0.800 \pm 0.01 \quad b$ & $0.809 \pm 0.01 \mathrm{a}$ & $* * *$ \\
\hline \multirow{4}{*}{60} & I.sanguinea & $0.774 \pm 0.02 a$ & $0.772 \pm 0.01 \mathrm{a}$ & $0.756 \pm 0.03 \mathrm{a}$ & $0.760 \pm 0.02 \mathrm{a}$ & ns \\
\hline & P.multifida & $0.757 \pm 0.02 \quad b$ & $0.774 \pm 0.01 \quad b$ & $0.792 \pm 0.03 \mathrm{a}$ & $0.794 \pm 0.02 \mathrm{a}$ & $* * *$ \\
\hline & V.coignetiae & $0.769 \pm 0.02 \mathrm{a}$ & $0.764 \pm 0.04 \quad \mathrm{a}$ & $0.762 \pm 0.03 \quad \mathrm{a}$ & $0.751 \pm 0.05$ a & ns \\
\hline & V. odoratissimum var. awabuki & $0.791 \pm 0.01 \quad b$ & $0.789 \pm 0.01 \quad b$ & $0.812 \pm 0.02 \mathrm{a}$ & $0.778 \pm .002 \mathrm{~b}$ & $* *$ \\
\hline \multirow{4}{*}{90} & I.sanguinea & $0.784 \pm 0.02 \mathrm{a}$ & $0.787 \pm 0.02 \mathrm{a}$ & $0.784 \pm 0.02 \quad \mathrm{a}$ & $0.797 \pm 0.02 \mathrm{a}$ & ns \\
\hline & P.multifida & $0.778 \pm 0.01 \quad \mathrm{a}$ & $0.763 \pm 0.05 \mathrm{a}$ & $0.766 \pm 0.02 \mathrm{a}$ & $0.783 \pm 0.02 \mathrm{a}$ & ns \\
\hline & V.coignetiae & $0.774 \pm 0.02 \mathrm{ab}$ & $0.769 \pm 0.02 b$ & $0.764 \pm 0.04 \quad b$ & $0.794 \pm 0.02 \mathrm{a}$ & ns \\
\hline & V. odoratissimum var. awabuki & $0.802 \pm 0.01 \mathrm{a}$ & $0.787 \pm 0.01 \mathrm{bc}$ & $0.800 \pm 0.01 \mathrm{ab}$ & $0.778 \pm 0.02 \mathrm{c}$ & $*$ \\
\hline
\end{tabular}

${ }^{\mathrm{z}}$ Different letters in the same row indicate significant difference according to Duncan's multiple range test, $p<.05$. $\mathrm{ns}, *{ }^{* *}$, and $* * *$ indicate no significance and significance at at $p<.05, p<.01$, and $p<.001$, respectively.

Table 3. Comparison of leaf area and wax content after the end of the experiment

\begin{tabular}{|c|c|c|c|c|c|c|}
\hline Leaf characteristics & Plant species & Control & Fly ash & Loam & Carbon black & Significance \\
\hline \multirow{4}{*}{$\begin{array}{l}\text { Leaf area } \\
\left(\mathrm{cm}^{2} / \text { pot }\right)\end{array}$} & I.sanguinea & $257.0 \mathrm{a}^{\mathrm{z}}$ & $138.6 \mathrm{a}$ & $167.7 \mathrm{a}$ & $250.1 \mathrm{a}$ & ns \\
\hline & P.multifida & $275.5 \mathrm{~b}$ & $302.9 \mathrm{~b}$ & $313.7 \mathrm{~b}$ & 742.4 a & $*$ \\
\hline & V.coignetiae & $134.5 \mathrm{a}$ & $116.6 \mathrm{a}$ & $126.1 \mathrm{a}$ & $168.5 \mathrm{a}$ & ns \\
\hline & V. odoratissimum var. awabuki & $258.5 \mathrm{a}$ & $261.0 \mathrm{a}$ & 310.4 a & 306.3 a & ns \\
\hline \multirow{4}{*}{$\begin{array}{l}\text { Wax content } \\
\left(\mu \mathrm{g} \mathrm{cm}^{-2} / \text { pot }\right)\end{array}$} & I.sanguinea & $45.1 \mathrm{a}$ & $151.1 \mathrm{a}$ & $115.3 \mathrm{a}$ & $138.8 \mathrm{a}$ & ns \\
\hline & P.multifida & 72.9 a & 61.9 a & $49.2 \mathrm{a}$ & $44.6 \mathrm{a}$ & ns \\
\hline & V.coignetiae & $69.0 \mathrm{a}$ & $60.8 \mathrm{a}$ & $69.2 \mathrm{a}$ & 52.6 a & ns \\
\hline & V. odoratissimum var. awabuki & $146.3 \mathrm{a}$ & $142.7 \mathrm{a}$ & $133.3 \mathrm{a}$ & $175.3 \mathrm{a}$ & ns \\
\hline
\end{tabular}

${ }^{\mathrm{z}}$ Different letters in the same row indicate significant difference according to Duncan's multiple range test, $p<.05$. ns, and $*$ indicate no significance and significance at at $p<.05$, respectively. 
and $V$. odoratissimum var. awabuki showed about 2-3 times higher wax content than the other three plant species.

We measured the PM per unit leaf area on the leaf surface (sPM10, sPM2.5) and PM on the wax layer (wPM10, wPM2.5) in 90 DAT (Table 4). sPM10 did not show a significant difference in only $P$. multifida, whereas in the other three plant species, it was the same as the control in carbon black and higher than the control in fly ash and loam. P. multifida did not show a significant difference in SPM10 by PM sources, but SPM2.5 showed a significant difference, mostly in loam. Łukowski et al. (2020) also revealed that Quercus robur did not show a difference in total PM depending on PM sources, and Betula pendula showed a significant difference only in cement out of three sources of PM (cement, construction, and roadside PM). I. sanguinea showed a significant difference in wPM10 by PM sources, whereas other wPM did not show a significant difference by PM sources. I. sanguinea showed a significant difference in wax content (Table 3) by PM sources, but the mean was 2-3 times higher in treatment, implying that wax content and wPM10 of I. sanguinea may have affected each other. In general, sPM is higher than wPM in many studies (Przybysz et al., 2014: Popek et al., 2017: Bui et al., 2021). However, in a study by Przybysz et al. (2014), wPM was higher than sPM in Pinus sylvestris in February when there is much rainfall, and there was more wax content than other seasons as well. Hedera helix showed high SPM at all times regardless of precipitation and also consistent wax content. Therefore, certain plants like $I$. sanguinea and Pinus sylvestris increase wax content and accumulate PM sources on the wax layer against non-hydrophilic PM sources that are not easily washed away with water.

\section{Conclusion}

This study examined physiological responses and PM removal capacity of four native plant species such as I. sanguinea, P. multifida, V. coignetiae, and Viburnum odoratissimum var. awabuki by constantly spraying different PM sources (loam, fly ash, carbon black). PM sources did not affect physiological responses of I. sanguinea, but wax content was 2-3 times higher in the PM sources compared to the control. The amount of

Table 4. The amount of particulate matter (PM) on the leaf surface and wax layer according to PM sources

\begin{tabular}{|c|c|c|c|c|c|c|}
\hline \multirow{2}{*}{ PM } & \multirow{2}{*}{ Species } & \multicolumn{4}{|c|}{ The amount of PM $\left(\mu \mathrm{g} \cdot \mathrm{cm}^{-2}\right)$} & \multirow{2}{*}{ Significance } \\
\hline & & Control & Fly ash & Loam & Carbon black & \\
\hline \multirow{4}{*}{ sPM10 } & I.sanguinea & $13.1 \pm 4.6 \mathrm{~b}^{\mathrm{z}}$ & $44.3 \pm 8.5 \mathrm{a}$ & $48.2 \pm 9.5 \mathrm{a}$ & $10.8 \pm 2.9 \mathrm{~b}$ & $* * *$ \\
\hline & P.multifida & $57.9 \pm 14.9$ a & $97.6 \pm 38.4 \mathrm{a}$ & $83.1 \pm 35.6$ a & $43.3 \pm 24.2 \mathrm{a}$ & ns \\
\hline & V.coignetiae & $19.8 \pm 7.1 \mathrm{~b}$ & $64.1 \pm 14.6 \mathrm{a}$ & $75.7 \pm 22.9$ a & $26.5 \pm 16.3 b$ & $* *$ \\
\hline & V. odoratissimum var. awabuki & $20.0 \pm 1.7 \mathrm{c}$ & $55.9 \pm 4.5 \mathrm{a}$ & $49.8 \pm 3.5 b$ & $16.9 \pm 1.6 \mathrm{c}$ & $* * *$ \\
\hline \multirow{4}{*}{ sPM2.5 } & I.sanguinea & $1.8 \pm 1.0 \mathrm{a}$ & $24.8 \pm 33.2 \mathrm{a}$ & $7.4 \pm 1.2 \mathrm{a}$ & $4.8 \pm 2.3 \mathrm{a}$ & ns \\
\hline & P.multifida & $6.0 \pm 2.1 \mathrm{~b}$ & $9.4 \pm 3.9 \mathrm{~b}$ & $38.7 \pm 0.3 \mathrm{a}$ & $5.7 \pm 2.6 \mathrm{~b}$ & $* * *$ \\
\hline & V.coignetiae & $1.8 \pm 2.0 \mathrm{a}$ & $7.0 \pm 1.1 \mathrm{a}$ & $11.3 \pm 11.0 \mathrm{a}$ & $5.8 \pm 2.5 \mathrm{a}$ & $\mathrm{ns}$ \\
\hline & V. odoratissimum var. awabuki & $0.3 \pm 0.4 \quad b$ & $4.8 \pm 2.26 \mathrm{a}$ & $5.6 \pm 1.5 \mathrm{a}$ & $4.3 \pm 0.6 \mathrm{a}$ & $* *$ \\
\hline \multirow{4}{*}{ wPM10 } & I.sanguinea & $13.5 \pm 4.9 b$ & $63.4 \pm 11.8 \mathrm{a}$ & $70.2 \pm 19.0$ a & $52.2 \pm 33.0 \mathrm{a}$ & $*$ \\
\hline & P.multifida & $38.6 \pm 8.4$ a & $45.7 \pm 15.8$ a & $38.8 \pm 2.3 \mathrm{a}$ & $28.5 \pm 10.9 a$ & ns \\
\hline & V.coignetiae & $26.3 \pm 20.1 \quad \mathrm{a}$ & $34.3 \pm 13.8 \mathrm{a}$ & $37.9 \pm 18.0 \mathrm{a}$ & $23.1 \pm 17.4$ a & ns \\
\hline & V. odoratissimum var. awabuki & $8.1 \pm 2.5 \mathrm{a}$ & $11.6 \pm 7.2 \mathrm{a}$ & $6.7 \pm 2.3 \mathrm{a}$ & $7.2 \pm 3.7 \mathrm{a}$ & ns \\
\hline \multirow{4}{*}{ wPM2.5 } & I.sanguinea & $2.8 \pm 2.2 \mathrm{a}$ & $5.7 \pm 1.5 \mathrm{a}$ & $2.6 \pm 2.0 \mathrm{a}$ & $5.2 \pm 2.2 \mathrm{a}$ & ns \\
\hline & P.multifida & $1.5 \pm 0.6 \mathrm{ab}$ & $1.6 \pm 0.8 \mathrm{ab}$ & $4.0 \pm 2.8 \mathrm{a}$ & $1.0 \pm 0.1 \mathrm{~b}$ & ns \\
\hline & V.coignetiae & $6.9 \pm 3.8 \mathrm{a}$ & $11.2 \pm 4.1 \mathrm{a}$ & $15.1 \pm 8.2 \mathrm{a}$ & $9.9 \pm 8.2$ a & ns \\
\hline & V. odoratissimum var. awabuki & $1.4 \pm 0.7 b$ & $1.8 \pm 0.3 \mathrm{ab}$ & $2.6 \pm 0.5 \mathrm{a}$ & $2.1 \pm 0.4 \mathrm{ab}$ & $\mathrm{ns}$ \\
\hline
\end{tabular}

${ }^{\mathrm{z}}$ Different letters in the same row indicate significant difference according to Duncan's multiple range test, $p<.05$. $\mathrm{ns},{ }^{*}, * *$ and $* * *$ indicate no significance and significance at at $p<.05, p<.01$, and $p<.001$, respectively. 
SPM10 was highest in fly ash and loam, whereas that of wPM10 was highest in all three PM sources. Therefore, $I$. sanguinea can be used effectively in removing PM10. $P$. multifida showed high Chl a, b, Tchl, and carotenoid content in carbon black in the 30 DAT, as well as high Fv/Fm and total leaf area after the experiment, thereby proving that carbon black helped plant growth. There was no significant difference in sPM10 and wPM depending on PM sources. However, sPM2.5 was high in fly ash and loam. Therefore, $P$. multifida can be used effectively in removing carbon black by planting it in areas with high carbon black concentration in the air. For $V$. coignetiae, PM sources did not affect growth, and there was no significant difference in PM amount except sPM10. However, it can be used as an economical landscaping tree since it can grow regardless of PM sources. $V$. odoratissimum var. awabuki showed lower Fv/Fm over time in the PM sources until 90 DAT, which shows that it must be observed longer. There was no significant difference in wPM, while sPM10 was highest in fly ash and loam. The amount of sPM2.5 was highest in all three PM sources, indicating that this plant is more effective in adsorption than absorption of PM.

Effective plants are selected by measuring the number of particles or weight, since there are limited PM sources that can be used as PM sources in PM removal experiments using plants. However, PM that are actually generated vary depending on the place, such as yellow dust, chemical plants, cement factories, and construction sites. Therefore, it is necessary to select effective plants based on characteristics of regional PM sources.

\section{References}

Bang, S.W., J.Y. Kim, J.E. Song, K.J. Kim, and D.H. Kim. 2013. Effect of the bio green wall system for the improvement of indoor environment. J. Korean Soc. People Plants Environ. 16(6):415-420. https://doi.org/10.11628/ksppe. 2013.16.6.415

Bui, H.T., U. Odsuren, K.J. Kwon, S.Y. Kim, J.C. Yang, N.R. Jeong, and B.J. Park. 2021. Assessment of air pollution tolerance and particulate matter accumulation of 11 woody plant species. Atmosphere 12(8):1067. https://doi.org/1

\subsection{0/atmos 12081067}

Chang, Y.D. and C.H. Lee. 2005. Effect of arsenic contents in soil on growth of several resources plants. Proceedings of the Plant Resources Society of Korea Conference, p. 158 .

Dominici, F., Y. Wang, A.W. Correia, M. Ezzati, A. Pope, and D.W. Dockery. 2015. Chemical composition of fine particulate matter and life expectancy: In 95 US counties between 2002 and 2007. Epidemiology 26(4):556-564. doi: 10.1097/EDE.0000000000000297

Dzierżanowski, K., R. Popek, H. Gawrońska, A. Sæbø, and S.W. Gawroński. 2011. Deposition of particulate matter of different size fractions on leaf surfaces and in waxes of urban forest species. Int. J. Phytoremediat. 13(10):1037-1046. https://doi.org/10.1080/15226514.2011.552929

Ebi, K.L. and G. McGregor. 2008. Climate change, tropospheric ozone and particulate matter, and health impacts. Environ. Health Perspect. 116(11):1449-1455. https://doi.org/10.1 289/ehp. 11463

Jeong, N.R., K.J. Kim, J.H. Yoon, S.W. Han, and S. You. 2020. Evaluation on the potential of 18 species of indoor plants to reduce particulate matter. J. People Plants Environ. 23(6):637-646. https://doi.org/10.11628/ksppe.2020.23. 6.637

Jeong, N.R., J.H. Kim, S.W. Han, J.C. Kim, and W.Y. Kim. 2021. Assessment of the particulate matter reduction potential of climbing plants on green walls for air quality management. J. People Plants Environ. 24(4):377-387. https://doi.org/10.11628/ksppe.2021.24.4.377

Kim, K.J. and E.H. Yoo. 2011. Efficiency of formaldehyde removal according to the ground cover plants and materials of indoor potted plants. J. Korean Soc. People Plants Environ. 14(5):279-283.

Kwon, H.J., J.S. Cho, and C.H. Lee. 2015. Effect of arsenic concentrations in soil on growth and arsenic accumulation of Pteris multifida. J. Korean Soc. People Plants Environ. 18(4): 273-280. https://doi.org/10.11628/ksppe.2015.18.4.273

Kwon, K.J. and B.J. Park. 2017. Effects of indoor greening method on temperature, relative humidity and particulate matter concentration. J. Korean Inst. Landsc. Archit. 45(4): 1-10. https://doi.org/10.9715/KILA.2017.45.4.001

Kwon, K.J., and B.J. Park. 2018. Particulate matter removal of indoor plants, Dieffenbachia amoena 'Marianne' and Spathiphyllum spp. according to light intensity. J Korean 
Inst. Landsc. Archit. 46(2):62-68. https://doi.org/10.971 5/KILA.2018.46.2.062

Kwon, K.J., O. Urrintuya, S.Y. Kim, J.C. Yang, J.W. Sung, and B.J. Park. 2020. Removal potential of particulate matter of 12 woody plant species for landscape planting. J. People Plants Environ. 23(6):647-654. https://doi.org/ 10.11628/ksppe.2020.23.6.647

Kwon, K.J., U. Odsuren, S.Y. Kim, J.C. Yang, and B.J Park. 2021. Comparison of the particulate matter removal capacity of 11 herbaceous landscape plants. J. People Plants Environ. 24(3):267-275. https://doi.org/10.11628/ ksppe.2021.24.3.267

Lee, C.H., B. Choi, and M.Y. Chun. 2015. Stabilizing soil moisture and indoor air quality purification in a walltyped botanical biofiltration system controlled by humidifying cycle. Korean J. Hortic. Sci. Technol. 33(4):605-617. https://doi.org/10.7235/hort.2015.15047

Li, C., Y. Huang, H. Guo, G. Wu, Y. Wang, W. Li, and L. Cui. 2019. The concentrations and removal effects of PM10 and PM2.5 on a wetland in Beijing. Sustainability 11(5):1312. https://doi.org/10.3390/su11051312

Lichtenthaler, H.K. 1987. Chlorophylls and carotenoids: Pigments of photosynthetic biomembranes. Methods Enzymol. 148:350-382. https://doi.org/10.1016/0076-6879(87)48036-1

Łukowski, A., R. Popek, and P. Karolewski. 2020. Particulate matter on foliage of Betula pendula, Quercus robur, and Tilia cordata: deposition and ecophysiology. Environ. Sci. Pollut. Res. 27:10296-10307. https://doi.org/10.1007/s1 1356-020-07672-0

Oh, S., K.H. Moon, I.C. Son, E.Y. Song, Y.E. Moon, and S.C. Koh. 2014. Growth, photosynthesis and chlorophyll fluorescence of chinese cabbage in response to high temperature. Korean J. Hortic. Sci. Technol. 32(3):318-329. https://doi.org/10.7235/hort.2014.13174

Ottelé, M., H.D. van Bohemen, and A.L.A. Fraaij. 2010. Quantifying the deposition of particulate matter on climber vegetation on living walls. Ecol. Eng. 36(2):154-162. https://doi.org/10.1016/j.ecoleng.2009.02.007

Park, J.S., J.H. Lee, and J.K. Suh. 2008. Effect of several indoor plants on indoor air pollutants removal -Focused on removing formaldehyde-. J. Korean Soc. People Plants Environ. 11(1):13-25.
Pope, C.A., R.T. Burnett, M.J. Thun, E.E. Calle, D. Krewski, K. Ito, and G.D. Thurston. 2002. Lung cancer, cardiopulmonary mortality, and longterm exposure to fine particulate air pollution. JAMA. 287(9):1132-1141. https://doi.org/10. 1001/jama.287.9.1132

Popek, R., A. Łukowski, and P. Karolewski. 2017. Particulate matter accumulation-further differences between native Prunus padus and non-native $P$. serotina. Dendrobiology 78:85-95. https://doi.org/10.12657/denbio.078.009

Przybysz, A., A. Sæbø, H.M. Hanslin, and S.W. Gawroński. 2014. Accumulation of particulate matter and trace elements on vegetation as affected by pollution level, rainfall and the passage of time. Sci. Total Environ. 481:360-369. https://doi.org/10.1016/j.scitotenv.2014.02.072

Sgrigna, G., C. Baldacchini, S. Dreveck, Z.Cheng, and C. Calfapietra. 2020. Relationships between air particulate matter capture efficiency and leaf traits in twelve tree species from an Italian urban-industrial environment. Sci. Total Environ. 718:137310. https://doi.org/10.1016/j.scit otenv.2020.137310

So, S.K. and J.H. Cho. 2018. The effect of eco-friendly characteristics on the price of office buildings. Korea Real Estate Rev. 28(2):49-64.

Yoon, J.W., K.C. Son, D. Yang, and S.J. Kays. 2009. Removal of indoor tobacco smoke under light and dark conditions as affected by foliage plants. Kor. J. Hortic. Sci. Technol. 27(2):312-318.

Yoon, Y.H. and K.S. Kim. 2018. Movement control of particulate pollutants in indoor air generated by voltage and frequency of alternating current. J. Korean Soc. Environ. Eng. 40(4):155-162. https://doi.org/10.4491/K SEE.2018.40.4.155

Zhang, W., B. Wang, and X. Niu. 2017. Relationship between leaf surface characteristics and particle capturing capacities of different tree species in Beijing. Forests 8(3):92. https://doi.org/10.3390/f8030092

Zhang, W., Y. Zhang, J. Gong, B. Yang, Z. Zhang, B. Wang, C. Zhu, J. Shi, and K. Yue. 2020. Comparison of the suitability of plant species for greenbelt construction based on particulate matter capture capacity, air pollution tolerance index, and antioxidant system. Environ. Pollut. 263:114615. https://doi.org/10.1016/j.envpol.2020.114615 